\title{
Cyclin-dependent kinase inhibitor p21 does not impact embryonic endochondral ossification in mice
}

\author{
NOBUAKI CHINZEI, SHINYA HAYASHI, SHINGO HASHIMOTO, NORIYUKI KANZAKI, \\ KENJIRO IWASA, SHUHEI SAKATA, SHINSUKE KIHARA, TAKAAKI FUJISHIRO, \\ RYOSUKE KURODA and MASAHIRO KUROSAKA
}

Department of Orthopedic Surgery, Kobe University Graduate School of Medicine, Kobe, Hyogo 650-0017, Japan

Received April 5, 2014; Accepted August 7, 2014

DOI: $10.3892 / \mathrm{mmr} .2014 .2889$

\begin{abstract}
Endochondral ossification at the growth plate is regulated by a number of factors and hormones. The cyclin-dependent kinase inhibitor p21 has been identified as a cell cycle regulator and its expression has been reported to be essential for endochondral ossification in vitro. However, to the best of our knowledge, the function of p21 in endochondral ossification has not been evaluated in vivo. Therefore, the aim of this study was to investigate the function of $\mathrm{p} 21$ in embryonic endochondral ossification in vivo. Wild-type (WT) and p21 knockout (KO) pregnant heterozygous mice were sacrificed on embryonic days E13.5, E15.5 and E18.5. Sagittal histological sections of the forearms of the embryos were collected and stained with Safranin O and 5-bromo-2'-deoxyuridine (BrdU). Additionally, the expression levels of cyclin D1, type II collagen, type $\mathrm{X}$ collagen, Sox9, and p16 were examined using immunohistochemistry, and the expression levels of p27 were examined using immunofluorescence. Safranin O staining revealed no structural change between the cartilage tissues of the WT and $\mathrm{p} 21 \mathrm{KO}$ mice at any time point. Type II collagen was expressed ubiquitously, while type $\mathrm{X}$ collagen was only expressed in the hypertrophic zone of the cartilage tissues. No differences in the levels of Sox 9 expression were observed between the two groups at any time point. The levels of cyclin D1 expression and BrdU uptake were higher in the E13.5 cartilage tissue compared with those observed in the embryonic cartilage tissue at subsequent time points. Expression of p16 and p27 was ubiquitous throughout the tissue sections. These results indicate that p21 may not be essential for embryonic endochondral ossification in articular cartilage of mice and that other signaling networks may compensate for p21 deletion.
\end{abstract}

Correspondence to: Dr Shinya Hayashi, Department of Orthopedic Surgery, Kobe University Graduate School of Medicine, 7-5-1 Kusunoki-cho, Chuo-ku, Kobe, Hyogo 650-0017, Japan E-mail: shayashi@med.kobe-u.ac.jp

Key words: endochondral ossification, cell cycle, p21, p27, mouse embryo

\section{Introduction}

The number of patients with cartilage disorders has been increasing globally (1). This is a complex issue compounded by the lack of a consensus on treatment; hence, the development of a conclusive therapy for cartilage disorders is necessary.

The process of cartilage tissue growth or longitudinal growth, also known as endochondral ossification, occurs within the long bones at the growth plate located between the epiphysis and the metaphysis $(2,3)$. At the growth plate, chondrogenic differentiation occurs from the diaphyseal side toward the metaphyseal side and chondrocytes are arranged longitudinally in a columnar shape, forming a layered structure. These organized chondrocytes are divided into three principal zones: The resting zone, the proliferative zone and the hypertrophic zone. The resting zone consists of small and immature chondrocytes, which differentiate into more mature chondrocytes in the proliferating zone. Large chondrocytes are found in the hypertrophic zone, where they exhibit a 5-10-fold increase in size (3). In the proliferative zone, chondrocytes produce numerous significant extracellular matrix proteins (ECM), including type II collagen and aggrican, which are structurally essential to the growth plate (4). In the hypertrophic zone, chondrocytes produce type $\mathrm{X}$ collagen as they cease to proliferate (5). In the adjacent metaphyseal zone, chondrocytes undergo apoptotic cell death, attract blood vessels and lay down a true bone matrix within the cartilage matrix (2). Thus, endochondral ossification is characterized by the continual proliferation, differentiation, and growth arrest of chondrocytes, and is regulated by a number of factors and hormones (2).

Cyclin-dependent kinases (CDKs) are widely recognized as regulators of cell cycle progression and CDK activation is regulated by CDK inhibitors (CKIs) (6,7). p21 is a CKI which has been identified as a cell cycle regulator; its induction by p53 during the DNA damage-induced $\mathrm{G}_{1}$-phase checkpoint response inhibits CDK4 and CDK2 (8-10). Asada et al (11) reported that cytoplasmic p21 also acts as an inhibitor of apoptosis and clinical research focusing on p21 has been conducted in the fields of angiology and oncology $(12,13)$. Furthermore, the association between the p53/p21 pathway and induced pluripotent stem cell generation has been established $(14,15)$. In the field of regenerative medicine, Bedelbaeva et al (16) 
reported that a $\mathrm{p} 21-\mathrm{knockout}$ mouse strain was able to close ear hole wounds and displayed increased morphological and histological regenerative responses when compared with the wild-type (WT) mouse strain, providing a firm link between cell cycle checkpoint control and tissue regeneration. Several studies have reported that the expression of p21 is essential for chondrogenesis in vitro $(17,18)$. Negishi et al (4) reported that the progression of chondrogenic differentiation requires the downregulation of CDK2-associated kinase activity with an increase in the levels of p21 protein, and the subsequent degradation of this protein via a proteasomal pathway. Despite studies which indicate the importance of p21, the original study of p21-knockout mice in 1995 described that these mice may develop normally (19). However, these results were reported strictly in adult mice from histological findings in areas such as muscles and vertebrae. Additionally, this study did not contain any information regarding the roles of p21 in the development of articular cartilage of limbs. The aim of the present study was to clarify the function of p21 in the embryonic endochondral ossification of articular cartilage in mice.

\section{Materials and methods}

Mouse breeding. All procedures were approved by the Animal Studies Committee at Kobe University, Kobe, Japan. p21 knockout mice (B6.129S6 (Cg)-Cdkn1atm1Led/J) were obtained from The Jackson Laboratory (Bar Harbor, ME, USA). All mice were housed in cages under pathogen-free conditions and were allowed unlimited access to water and food.

The mice were bred in the animal facility at Kobe University Graduate School of Medicine (Kobe, Japan). To generate heterozygous mice, homozygous p21 knockout (KO) and WT mice (C57BL/6J; CLEA Japan, Inc., Tokyo, Japan) were mated. Next, heterozygous mice were mated to obtain embryos from the two groups of mice: p21 KO and WT. A total of ten mice were used for each experiment.

Tissue harvesting and decalcification. Pregnant heterozygous mice were anesthetized by an intraperitoneal injection of pentobarbital $(50 \mathrm{mg} / \mathrm{kg})$ and sacrificed by cervical disolcation at embryonic days E13.5, E15.5 and E18.5 (n=10 for each time point). Following collection of the embryos, the embryo forearms were dissected, fixed in $4 \%$ paraformaldehyde buffered with phosphate-buffered saline (PBS), decalcified with $10 \%$ formic acid and embedded in paraffin. Sagittal histological sections were cut at a thickness of $6 \mu \mathrm{m}$ using a microtome and stained with Safranin O (Tokyo Chemical Industry Co., Ltd., Tokyo, Japan) and 5-bromo-2'-deoxyuridine (BrdU; BD Biosciences, San Jose, CA, USA). Tissue sections were also subjected to immunohistochemical and immunofluorescence analyses.

BrdU labeling and staining. To confirm the cell cycle progression at the $G_{1} / S$ phase, pregnant mice were injected intraperitoneally with $200 \mu \mathrm{l}$ BrdU and sacrificed by cervical dislocation $2 \mathrm{~h}$ later to obtain embryonic tissues. Staining was performed using a BrdU In-Situ Detection kit (BD Biosciences, Franklin Lakes, NJ, USA) according to the manufacturer's instructions and the sections were examined using a BZ-8100 confocal microscope (Keyence, Osaka, Japan).

Genotyping of mouse embryos. Genotypes were verified by polymerase chain reaction (PCR) analysis of tail-derived DNA. Genomic DNA was extracted using the DNeasy Blood \& Tissue kit (Qiagen, Valencia, CA, USA). p21 deletion was confirmed by the presence of a 447-bp fragment unique to the mutant genotype, which was amplified with a p21-specific forward primer (5'-GTTGTCCTCGCCCTCATCTA-3') and a mutant reverse primer (5'-CTGTCCATCTGCACGAGACTA-3') (sequences provided by The Jackson Laboratory). WT alleles were confirmed by the presence of a $240 \mathrm{bp}$ fragment amplified with the WT reverse primer (5'-GCCTATGTTGGGAAACCAGA-3') and the p21-specific forward primer. DNA amplification was performed under the following PCR conditions: $94^{\circ} \mathrm{C}$ for $5 \mathrm{~min}$, followed by 40 cycles of $94^{\circ} \mathrm{C}$ for $30 \mathrm{sec}, 55^{\circ} \mathrm{C}$ for $30 \mathrm{sec}$ and $72^{\circ} \mathrm{C}$ for $30 \mathrm{sec}$, and ending with $72^{\circ} \mathrm{C}$ for $2 \mathrm{~min}$.

Immunohistochemistry. De-paraffinized sections were digested with proteinase (Dako Retrieval Solution Ready-to-Use; Dako, Glostrup, Denmark) for $20 \mathrm{~min}$ and treated with 3\% hydrogen peroxide (Wako Pure Chemical Industries, Osaka, Japan) to block endogenous peroxidase activity. In addition to BrdU staining, the expression of cyclin D1 was examined to determine cell cycle progression at the $G_{1} / S$ phase, as cyclin $D 1$ is a $G_{1} / S$ phase-specific protein (20). Furthermore, the expression levels of p16, type II collagen, type $\mathrm{X}$ collagen, and Sox 9 were examined. INK4 is a tumor suppressor protein which causes $G_{1}$ phase cell cycle arrest and p16 is a known representative of the INK4 family (21). Type II collagen is the foundation for articular cartilage and hyaline cartilage and it has been established that type $\mathrm{X}$ collagen is produced by hypertrophic chondrocytes (4). Sox9 is essential for chondrocyte differentiation and cartilage formation (22). Tissue sections were treated overnight at $4^{\circ} \mathrm{C}$ in Can Get Signal immunostain solution A (Toyobo, Tokyo, Japan) and the following antibodies: rabbit anti-mouse cyclin D1 polyclonal antibody (1:50 dilution; Cell Signaling Technology, Inc., Danvers, MA, USA), rabbit anti-mouse p16 polyclonal antibody (1:50 dilution; Abbiotec LLC, San Diego, CA, USA), rabbit anti-mouse type II collagen polyclonal antibody (1:100 dilution; Cosmo Bio Co., Ltd, Tokyo, Japan), rabbit anti-mouse type X collagen polyclonal antibody (1:50 dilution; Cosmo Bio Co., Ltd) and rabbit anti-mouse Sox9 polyclonal antibody (1:100 dilution; Abcam, Cambridge, UK). Subsequently, the sections were treated with horseradish peroxidase (HRP)-conjugated goat anti-rabbit immunoglobulin anitibody (N-Histofine ${ }^{\circledR}$ Simple Stain Mouse MAX PO (R); Nichirei Bioscience, Tokyo, Japan) at room temperature for $30 \mathrm{~min}$. The signal was developed as a brown reaction product using the peroxidase substrate 3,3'-diaminobenzidine (Histofine Simple Stain DAB solution; Nichirei Bioscience), and the sections were examined using a BZ-8000 Confocal microscope (Keyence, Osaka, Japan).

Immunofluorescence. Deparaffinized sections were digested with proteinase (Dako Retrieval Solution Ready-to-Use) for 


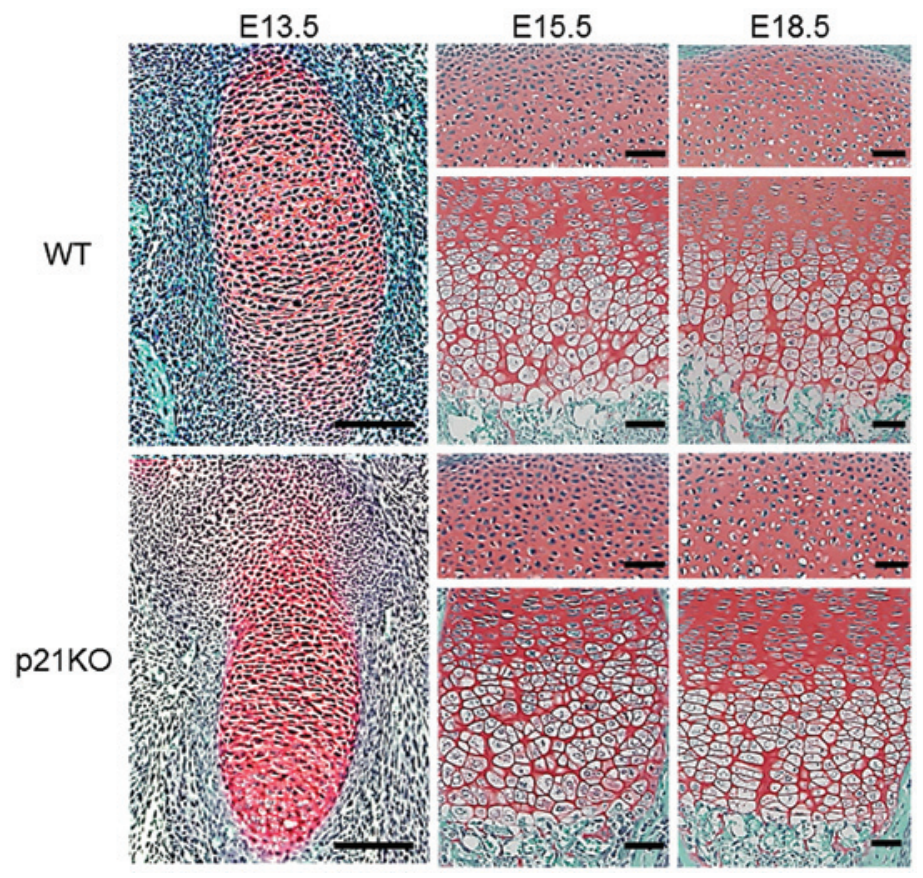

Figure 1. Safranin O staining in E13.5, E15.5 and E18.5 cartilage tissues. Upper panels, wild-type (WT) mice; lower panels, p21 knockout (KO) mice (scale bars, $100 \mu \mathrm{m}$ ).

20 min and treated overnight at $4^{\circ} \mathrm{C}$ with the following antibodies in Can Get Signal immunostain solution A: Rabbit anti-mouse p27 polyclonal antibody (1:50 dilution; Santa Cruz Biotechnology, Inc.). The secondary antibodies used were goat anti-rabbit immunoglobulin Alexa Fluor 488 (1:200 dilution; Life Technologies, Carlsbad, CA, USA) for $30 \mathrm{~min}$ at room temperature. The nuclei were stained with DAPI and images were captured using a BZ-8000 confocal microscope (Keyence).

Statistical analysis. Statistical analysis was performed using the SPSS version 16.0 software package (SPSS, Inc., Chicago, IL, USA). The differences in the percentages of cyclin D1 or BrdU-positive cells between the groups at each time point were analyzed using the Mann Whitney U-test. $\mathrm{P}<0.05$ was considered to indicate a statistically significant difference. All data are expressed as the mean \pm standard deviation.

\section{Results}

Cartilage tissue morphology in embryonic mice is not altered by 221 deficiency. To investigate the in vivo function of $\mathrm{p} 21$ in chondrogenesis, a histological analysis of cartilage tissues was performed at E13.5, E15.5 and E18.5. Safranin O staining revealed no structural changes at any time point between the embryonic cartilage tissues of WT and p21KO mice (Fig. 1). These results indicate that 21 deficiency does not alter the morphology of embryonic cartilage tissue in mice.

Expression of ECM proteins and Sox 9 is not altered by 21 deficiency. To investigate the in vivo function of $\mathrm{p} 21$ in ECM production, immunohistochemical analysis of cartilage tissue was performed at E13.5, E15.5, and E18.5. Type II collagen was expressed ubiquitously in the cartilage tissues. However, no differences were found between the embryonic cartilage tissues of WT and p21KO mice at any time point (Fig. 2A). Type $\mathrm{X}$ collagen was expressed in the hypertrophic zone. However, no differences were found between the embryonic cartilage tissues of WT and p21KO mice at each time point (Fig. 2B).

Immunohistochemical analysis revealed that the Sox 9 expression levels of WT and $\mathrm{p} 21 \mathrm{KO}$ mice did not differ at each time point (Fig. 2C). These results indicate that p21 deficiency does not affect ECM production in endochondral ossification.

Chondrocyte proliferation is not altered by $p 21$ deficiency. The main function of $\mathrm{p} 21$ is as a negative regulator of the $\mathrm{G}_{1} / \mathrm{S}$ transition, inducing ' $\mathrm{G}_{1}$ arrest' (23). Cyclin D1 staining was performed to evaluate the cell cycle progression at the $\mathrm{G}_{1}$ phase. Cyclin D1 forms complexes with CDK4 or CDK6, whose activity is required for $\mathrm{G}_{1} / \mathrm{S}$ phase transition (7). Although the expression levels of cyclin D1 were higher in the E13.5 cartilage tissue compared with those at subsequent time points, no differences were found between the WT and p21KO mice (Fig. 3A). Enumeration of cyclin D1-positive chondrocytes showed significant decreases at E15.5 and E18.5 compared with that of E13.5 $(\mathrm{P}<0.05)$. However, no significant inter-group differences were identified at any time point $(\mathrm{P}>0.05)$ (Fig. 3B).

BrdU staining was performed as BrdU is incorporated into proliferating cells (S phase) allowing it to be used to evaluate DNA replication (24). The uptake of BrdU appeared to be much higher in the E13.5 cartilage tissue compared with that at subsequent time points. However, no differences in BrdU uptake were observed between the WT and p21KO mice (Fig. 3C). The number of BrdU-positive chondrocytes was significantly reduced at E15.5 and E18.5 compared with the number at E13.5 

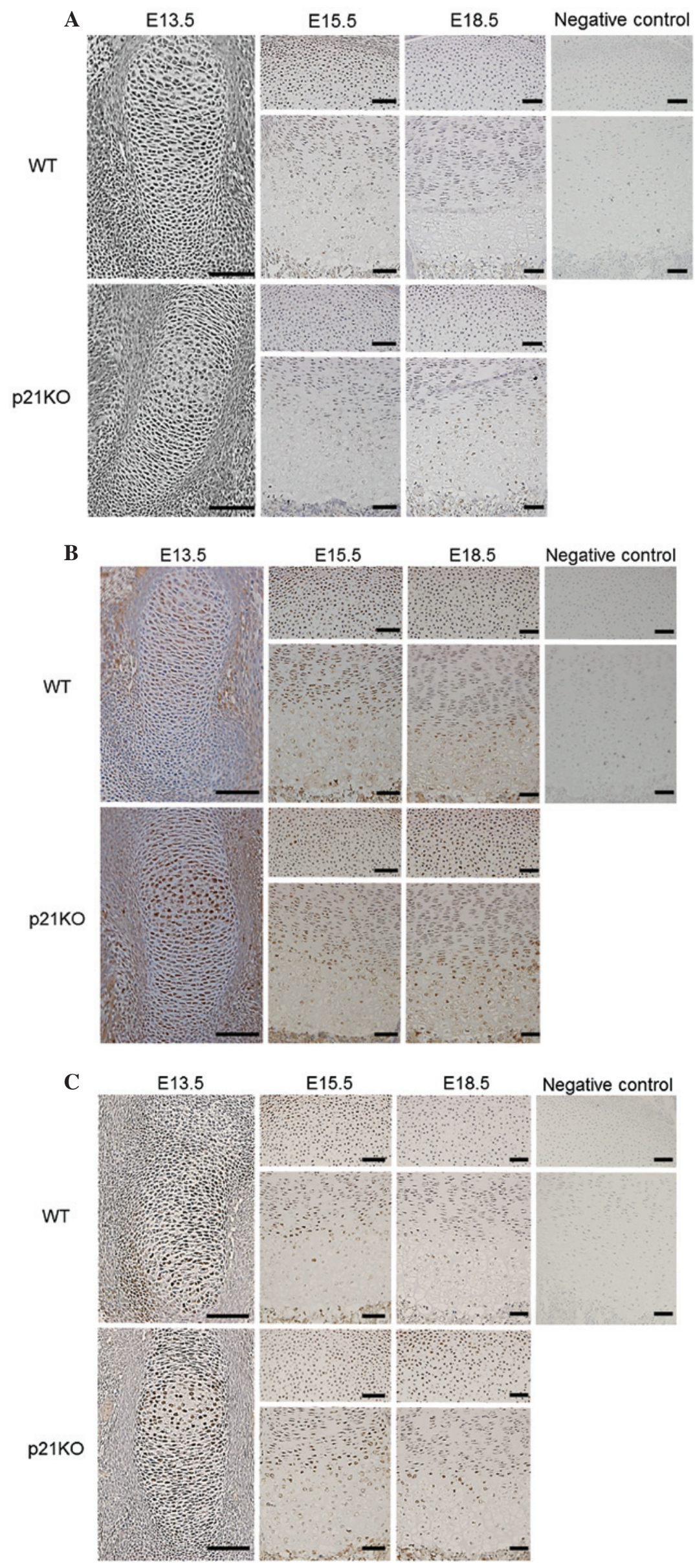

Figure 2. Expression of type II collagen, type X collagen and Sox9 in the mouse embryo. The expression of (A) type II collagen, (B) type X collagen and (C) Sox9 in E13.5, E15.5 and E18.5 cartilage tissues. Upper panels, wild-type (WT) mice; lower panels, p21 knockout (KO) mice (scale bars, $100 \mu \mathrm{m}$ ). 


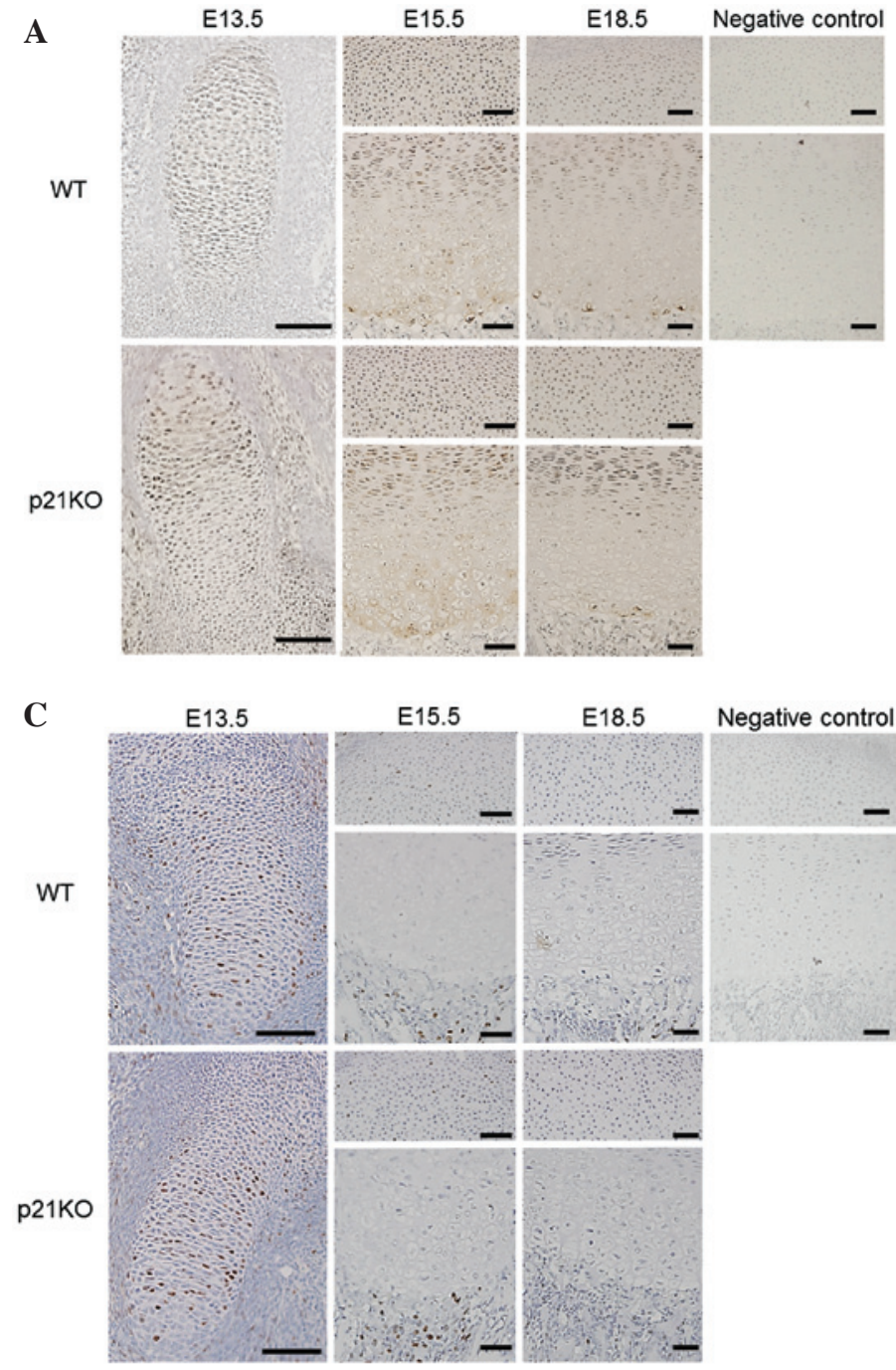

$\mathbf{B}$

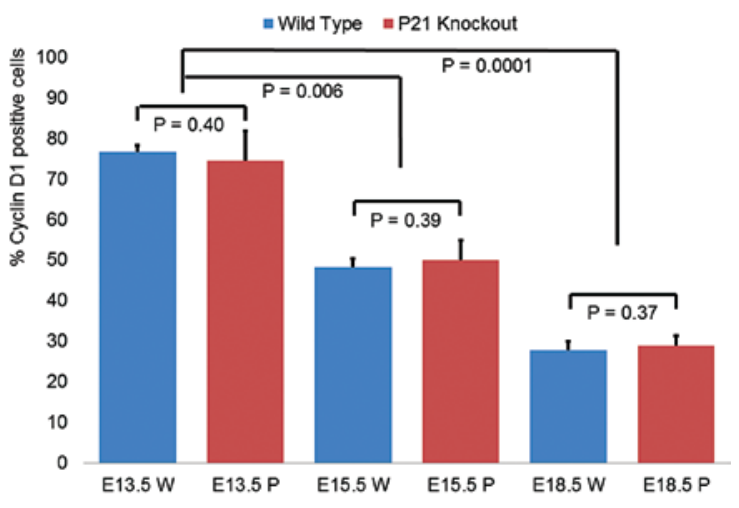

D

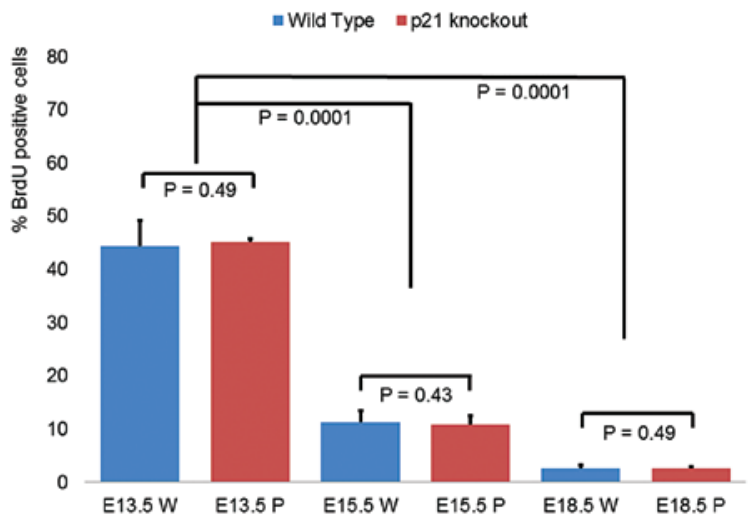

Figure 3. Cyclin D1 expression and 5-bromo-2'-deoxyuridine (BrdU) uptake in the mouse embryo. (A) The expression of cyclin D1 in E13.5, E15.5 and E18.5 cartilage tissues. Upper panels, wild-type (WT) mice; lower panels, p21 knockout (KO) mice (scale bars, $100 \mu \mathrm{m}$ ). (B) Quantitative analysis of cyclin D1 positive cells. Three micrographs of the growth plate were captured under $\mathrm{x} 40$ magnification. The percentage of cyclin D1 positive cells was calculated as the ratio of the total number of cyclin D1 positive cells to the total number of chondrocytes. (C) The uptake of BrdU in E13.5, E15.5 and E18.5 cartilage tissues. Upper panels, WT; lower panels, p21KO (scale bars, $100 \mu \mathrm{m}$ ). (D) Quantitative analysis of BrdU positive cells. Three micrographs of the growth plate were captured under $\times 40$ magnification. The percentage of BrdU positive cells was calculated as the ratio of the total number of BrdU positive cells to the total number of chondrocytes. $\mathrm{P}<0.05$ was considered to indicate a statistically significant difference.

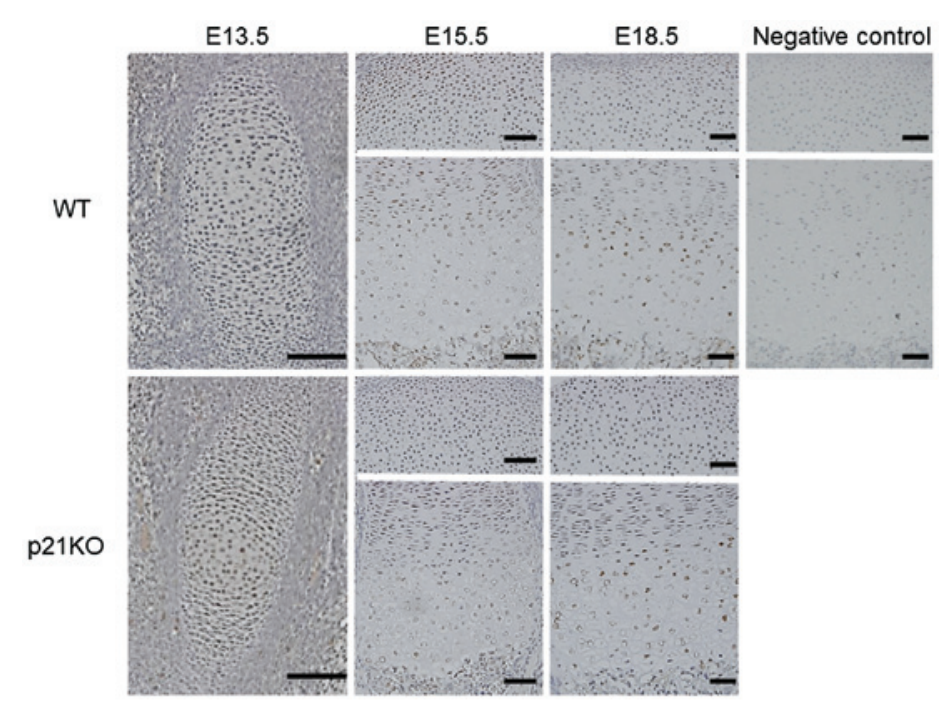

Figure 4. Expression of p16 in E13.5, E15.5 and E18.5 cartilage tissues. Upper panels, wild-type (WT) mice; lower panels, p21 knockout (KO) mice (scale bars, $100 \mu \mathrm{m}$ ). 
A

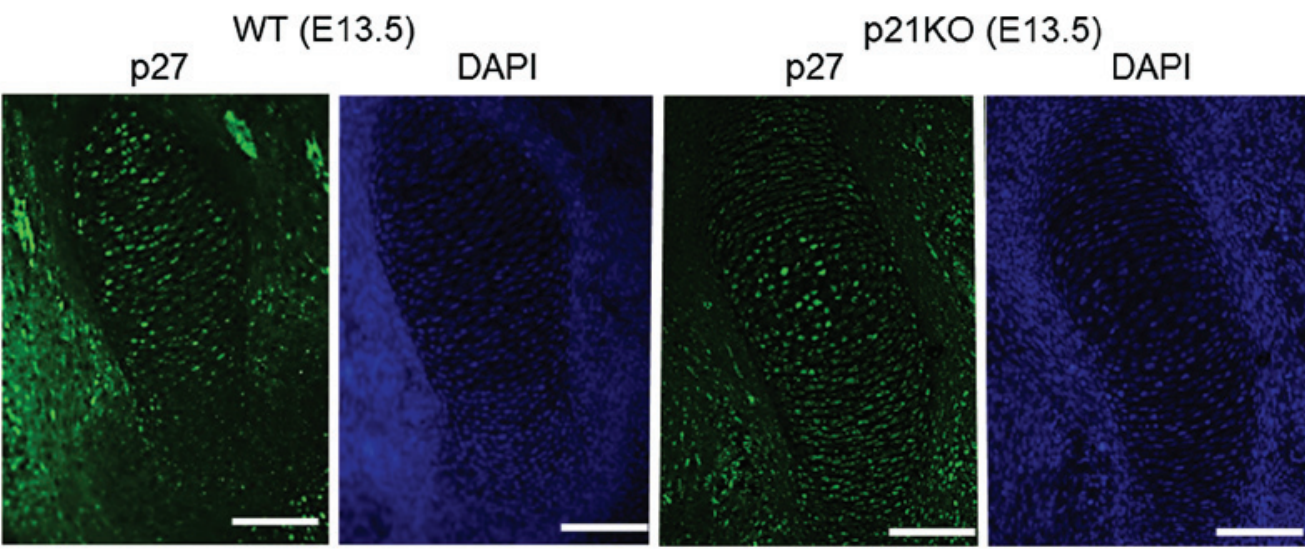

B

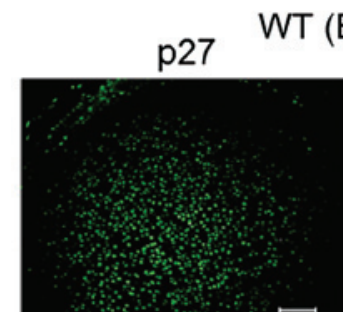

(E15.5) DAPI
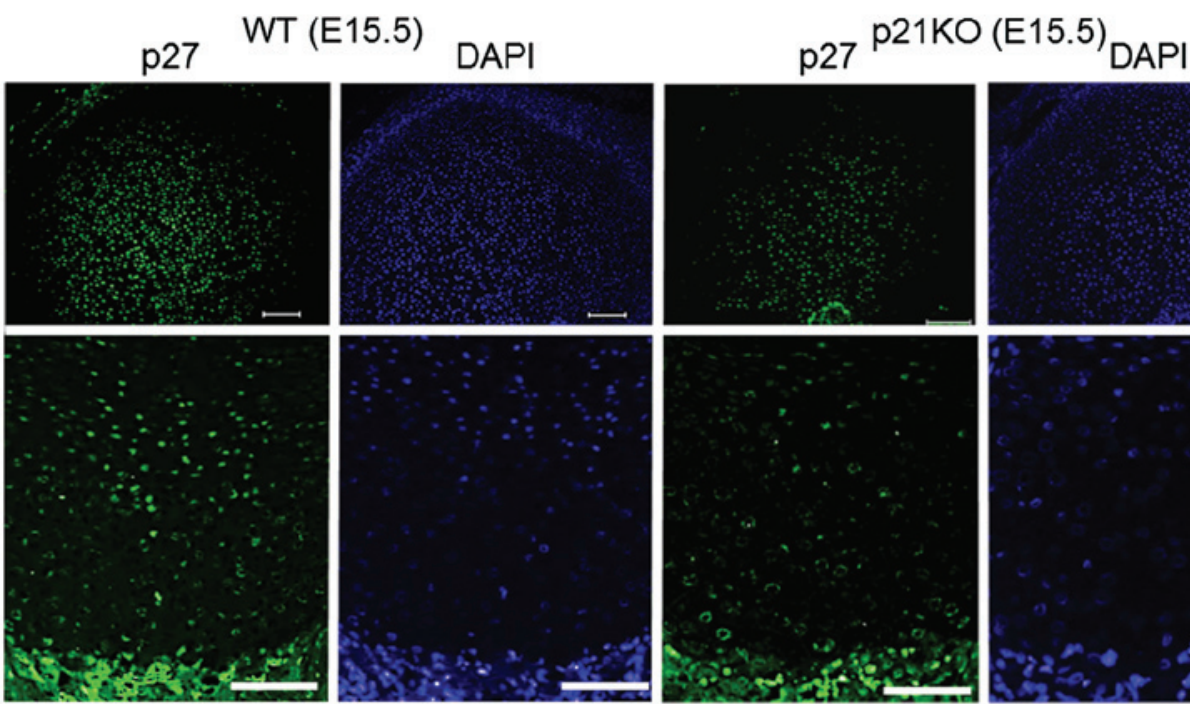

C
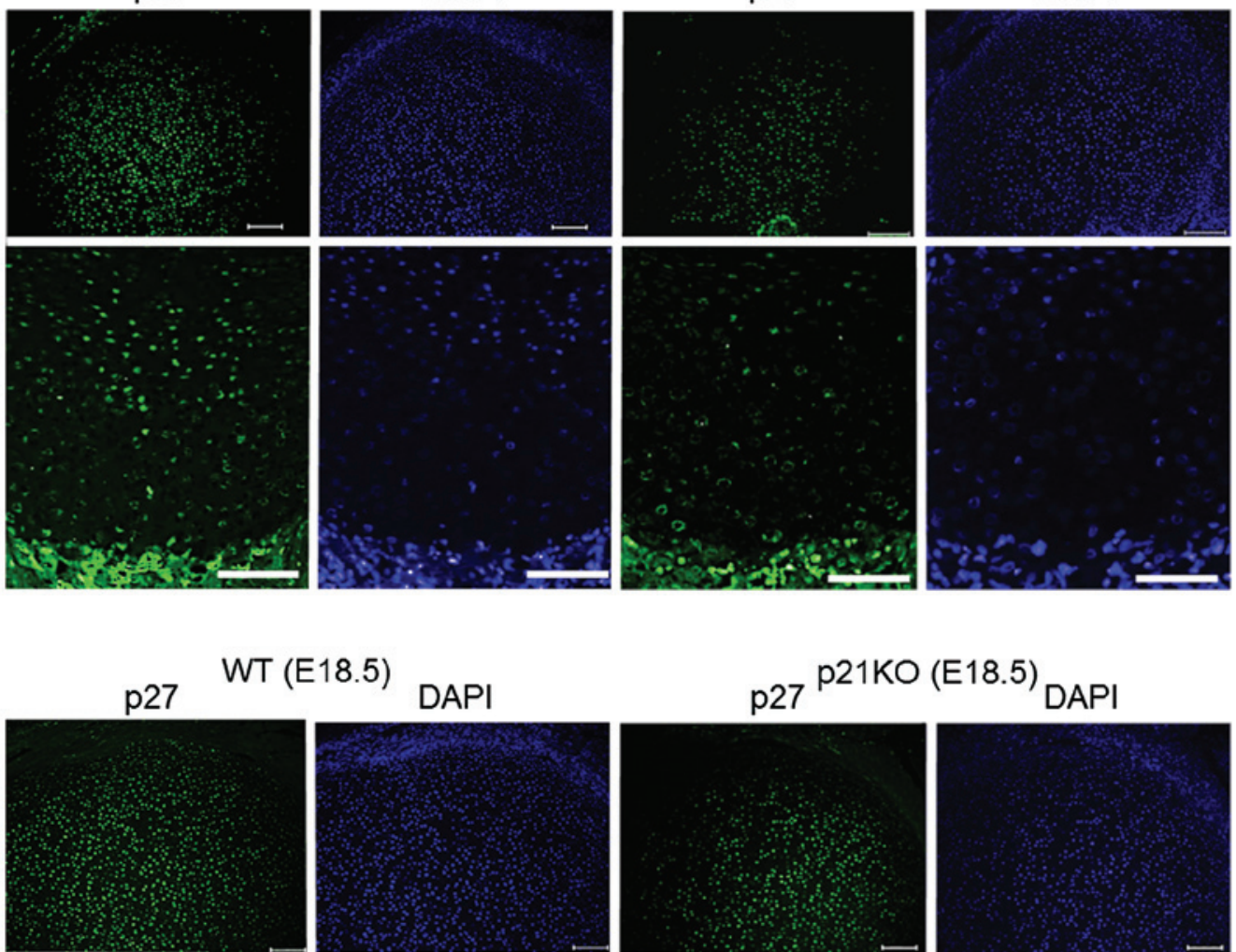

18.5) DAPI

p27

${ }^{(E 18.5)}$ DAPI
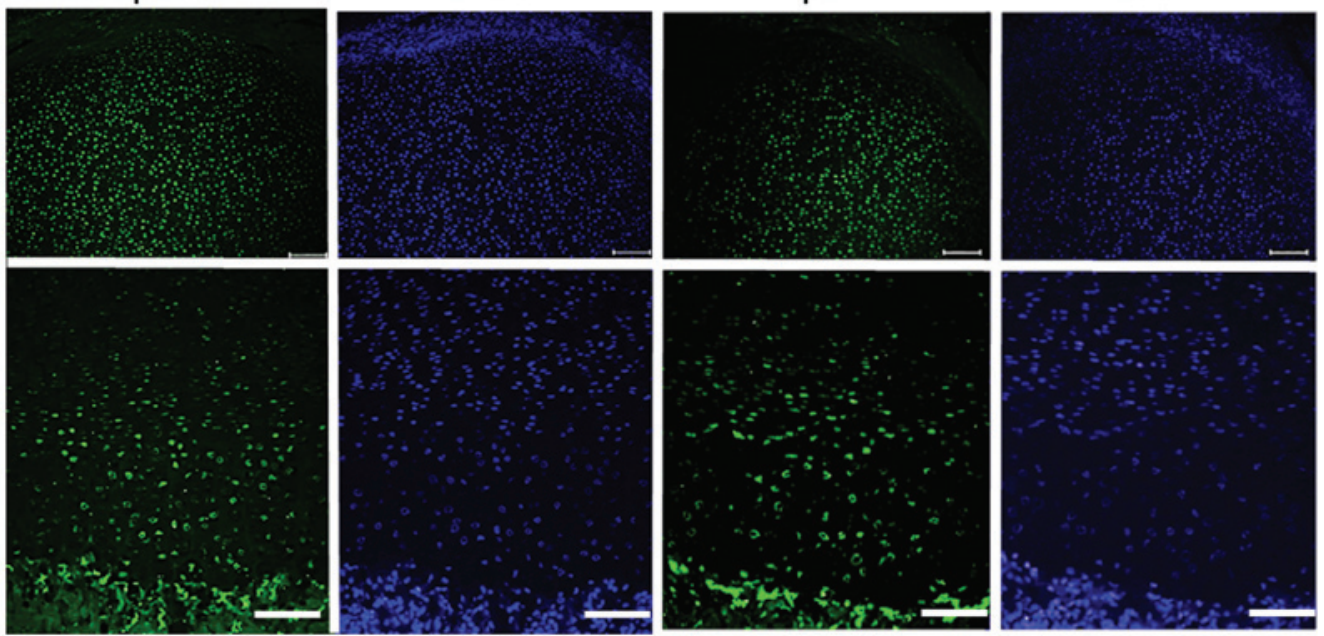

Figure 5. Immunofluorescence analysis of p27 expression in the mouse embryo with DAPI staining. The expression of p27 in (A) E13.5, (B) E15.5 and (C) E18.5 p21 knockout (KO) and wild-type (WT) mice (scale bars, $100 \mu \mathrm{m}$ ).

$(\mathrm{P}<0.05)$. However, no significant differences between the two groups were observed at each time point ( $\mathrm{P}>0.05$ ) (Fig. 3D). These results indicate that $\mathrm{p} 21$ deficiency does not affect chondrocyte proliferation and that chondrocyte proliferation is naturally more active during the early embryonic period.
Evaluation of the expression levels of p16. INK4 is a tumor suppressor and cell cycle regulatory protein that acts during the $G_{1}$ phase. p16 is a known representative of the INK4 family which interacts with CDK4 and CDK6, inhibiting their ability to interact with cyclin D (25). While p16 was expressed ubiq- 
uitously throughout the tissue sections, no differences were observed between the expression levels in the WT and p21KO mice (Fig. 4).

Immunofluorescence evaluation of the expression of $p 27$. The expression of $\mathrm{p} 27$, one of the Cip/Kip family components, was evaluated by immunofluorescence and DAPI staining (Fig. 5A-C). p27 was ubiquitously expressed throughout the tissue sections, however, no differences were observed between the expression levels in the WT and p21KO mice (Fig. 5).

\section{Discussion}

Accurate control of the cell cycle is essential for normal development, and CDKs are an integral part of cell cycle regulation (26). CDKs are specifically regulated by CKIs. Two distinct families of CKIs are known: Cip/Kip and INK4. The INK4 family consists of p15 ${ }^{\mathrm{INK} 4 \mathrm{~b}}, \mathrm{p} 16^{\mathrm{INK} 4 \mathrm{a}}, \mathrm{p} 18^{\mathrm{INK} 4 \mathrm{c}}$ and p19 ${ }^{\text {INK4d }}$, which specifically inhibit the activity of $\mathrm{G}_{1}$-phase cyclin D-CDK4 and CDK6 $(7,25)$. The Cip/Kip family, including $\mathrm{p} 21^{\mathrm{CIP} 1}, \mathrm{p} 27^{\mathrm{KIP} 1}$ and $\mathrm{p} 57^{\mathrm{KIP} 2}$, controls a broader spectrum of cyclin-CDK complexes, including CDK2, CDK3, CDK4 and CDK6 (7,27). Although members of the CIP/KIP family possess a few similar functions, they also possess different functions which are determined by the differences in expression pattern and protein structure.

Previous studies have reported that p27 has an important role in endochondral ossification. In p27KO mice, multiple organ overgrowth has been observed (28) and Emons et al (29) reported that $\mathrm{p} 27 \mathrm{KO}$ mice demonstrated a modest increase in body length. Furthermore, the expression levels of p27 mRNA were similar throughout the hypertrophic and resting/proliferative zones in adult mice. In the present study, p27 was ubiquitously expressed in the tissue sections assessed.

Previous studies have reported that $\mathrm{p} 21$ is expressed in the majority of organs and tissues during murine embryonic and postnatal development $(30,31)$. In myogenesis, the muscle-specific transcription factor MyoD induces p21 expression in association with the terminal differentiation of muscles (31), suggesting that p21 has a crucial role in muscle development (6). In the current study, it was demonstrated that p21 deficiency did not alter the morphology of embryonic cartilage tissue in mice, although p21 has been shown to be expressed in the proliferative and hypertrophic zones in adult WT mice (32). Furthermore, p21 deficiency did not affect ECM production or Sox 9 expression.

Additionally, the expression of cyclin D1 and INK4 family members was evaluated. The expression levels of cyclin D1 and p16 did not differ between the WT and p21KO mice. The similarity of the expression levels of cyclin D1 and p16 indicates that there are no differences in the remaining activities of $\mathrm{G}_{1}$-phase that the $\mathrm{Cip} / \mathrm{Kip}$ family are involved in. The uptake of BrdU was observed to be much higher at E13.5 compared with E15.5 and E18.5. However, no differences in BrdU uptake were found between WT and p21KO mice, revealing that the rate of development was equivalent. Taking these results into consideration, p21 deficiency did not affect chondrocyte proliferation.

Therefore, the primary finding of the current study is that p21 may not be essential for embryonic articular chondrogen- esis in mice. Negishi et al (26) reported that the reduction of endogenous p21 caused inhibition of early chondrogenic differentiation in ATDC5 cells, indicating that the p21 gene has an important role in this cellular process in vitro (26). However, the current study did not observe any marked changes in vivo, revealing a discrepancy in these findings. While the impact of these results within the general scientific community may not be great, the results obtained from the $\mathrm{KO}$ mice provide important information for the researchers in relevant fields. These results revealed that $\mathrm{p} 21$ deficiency does not impact the morphology, ECM formation, chondrocytic marker protein production, chondrocyte proliferation or cell cycle regulatory proteins in the developing cartilage.

It has been hypothesized that various complicated mechanisms control the expression and timing of the Cip/Kip family, which appear to possess important roles in development and growth regulation (6). Therefore, p21 deletion may be compensated by a complicated mechanism involving other networks. Further studies are required to gain insight into these phenomena. A clear understanding of these mechanisms may lead to the development of novel therapeutic strategies for cartilage disorders.

In conclusion, the current study revealed that $\mathrm{p} 21$ does not impact embryonic endochondral ossification in articular cartilage of mice. Furthermore, compensation for the lack of p21 function does not appear to be mediated by components of the Cip/Kip family, p27.

\section{Acknowledgements}

This study was presented at the Orthopaedic Research Society Annual Meeting, 2014 (Poster no. 1322). The authors thank Ms. Kyoko Tanaka, Ms. Minako Nagata, Ms. Maya Yasuda, Mr. Takeshi Ueha for their technical assistance and Dr Mitsuru Morimoto for technical assistance and giving critical suggestions.

\section{References}

1. Cross M, Smith E, Hoy D, et al: The global burden of hip and knee osteoarthritis: estimates from the global burden of disease 2010 study. Ann Rheum Dis 3: 1323-1330, 2014.

2. Kronenberg HM: Developmental regulation of the growth plate. Nature 423: 332-336, 2003.

3. Emons J, Chagin AS, Sävendahl L, Karperien M and Wit JM: Mechanisms of growth plate maturation and epiphyseal fusion. Hormone Res Paediatr 75: 383-391, 2011.

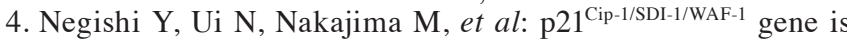
involved in chondrogenic differentiation of ATDC5 cells in vitro. J Biol Chem 276: 33249-33256, 2001.

5. Schmid TM and Linsenmayer TF: Immunohistochemical localization of short chain cartilage collagen (type X) in avian tissues. J Cell Biol 100: 598-605, 1985.

6. Nakayama K and Nakayama K: Cip/Kip cyclin-dependent kinase inhibitors: brakes of the cell cycle engine during development. BioEssays 20: 1020-1029, 1998.

7. Sherr CJ and Roberts JM: CDK inhibitors: positive and negative regulators of G1-phase progression. Genes Dev 13: 1501-1512, 1999.

8. He G, Siddik ZH, Huang Z, et al: Induction of p21 by p53 following DNA damage inhibits both $\mathrm{Cdk} 4$ and Cdk2 activities. Oncogene 24: 2929-2943, 2005.

9. Seoane J, Le HV and Massagué J: Myc suppression of the p21(Cip1) Cdk inhibitor influences the outcome of the p53 response to DNA damage. Nature 419: 729-734, 2002.

10. Harper JW, Adami GR, Wei N, Keyomarsi K and Elledge SJ: The p21 Cdk-interacting protein Cip1 is a potent inhibitor of G1 cyclin-dependent kinases. Cell 75: 805-816, 1993. 
11. Asada M, Yamada T, Ichijo H, et al: Apoptosis inhibitory activity of cytoplasmic p21(Cip1/WAF1) in monocytic differentiation. EMBO J 18: 1223-1234, 1999.

12. Olive M, Mellad JA, Beltran LE, et al: $\mathrm{p} 21^{\mathrm{Cip} 1}$ modulates arterial wound repair through the stromal cell-derived factor-1/CXCR4 axis in mice. J Clin Invest 118: 2050-2061, 2008.

13. Gartel AL and Radhakrishnan SK: Lost in transcription: $\mathrm{p} 21$ repression, mechanisms, and consequences. Cancer Res 65 3980-3985, 2005.

14. Hong H, Takahashi K, Ichisaka T, et al: Suppression of induced pluripotent stem cell generation by the p53-p21 pathway. Nature 460: 1132-1135, 2009.

15. Kawamura T, Suzuki J, Wang YV, et al: Linking the p53 tumour suppressor pathway to somatic cell reprogramming. Nature 460 1140-1144, 2009.

16. Bedelbaeva K, Snyder A, Gourevitch D, et al: Lack of p21 expression links cell cycle control and appendage regeneration in mice. Proc Natl Acad Sci USA 107: 5845-5850, 2010.

17. Aikawa T, Segre GV and Lee K: Fibroblast growth factor inhibits chondrocytic growth through induction of p21 and subsequent inactivation of cyclin E-Cdk2. J Biol Chem 276: 29347-29352, 2001.

18. Nakajima M, Negishi $Y$, Tanaka $H$ and Kawashima $K$ : p21(Cip-1/SDI-1/WAF-1) expression via the mitogen-activated protein kinase signaling pathway in insulin-induced chondrogenic differentiation of ATDC5 cells. Biochem Biophys Res Commun 320: 1069-1075, 2004.

19. Deng C, Zhang P, Harper JW, Elledge SJ and Leder P: Mice lacking $21^{\mathrm{CIPI} / \mathrm{WAF} 1}$ undergo normal development, but are defective in G1 checkpoint control. Cell 82: 675-684, 1995.

20. Baldin V, Lukas J, Marcote MJ, Pagano M and Draetta G: Cyclin D1 is a nuclear protein required for cell cycle progression in G1. Genes Dev 7: 812-821, 1993.

21. Byeon IJ, Li J, Ericson K, et al: Tumor suppressor p16 ${ }^{\mathrm{INK} 4 \mathrm{~A}}$ : determination of solution structure and analyses of its interaction with cyclin-dependent kinase 4. Mol Cell 1: 421-431, 1998.
22. Bi W, Deng JM, Zhang Z, Behringer RR and de Crombrugghe B: Sox9 is required for cartilage formation. Nat Genet 22: 85-89, 1999.

23. Niculescu AB III, Chen X, Smeets M, Hengst L, Prives C and Reed SI: Effects of p21(Cip1/Waf1) at both the G1/S and the $\mathrm{G} 2 / \mathrm{M}$ cell cycle transitions: $\mathrm{pRb}$ is a critical determinant in blocking DNA replication and in preventing endoreduplication. Mol Cell Biol 18: 629-643, 1998.

24. Gratzner HG: Monoclonal antibody to 5-bromo- and 5-iododeoxyuridine: A new reagent for detection of DNA replication. Science 218: 474-475, 1982.

25. Cánepa ET, Scassa ME, Ceruti JM, et al: INK4 proteins, a family of mammalian CDK inhibitors with novel biological functions. IUBMB Life 59: 419-426, 2007.

26. Sherr CJ: G1 phase progression: cycling on cue. Cell 79: $551-555,1994$.

27. LaBaer J, Garrett MD, Stevenson LF, et al: New functional activities for the p21 family of CDK inhibitors. Genes Dev 11: 847-862, 1997.

28. Kiyokawa H, Kineman RD, Manova-Todorova KO, et al: Enhanced growth of mice lacking the cyclin-dependent kinase inhibitor function of p27(Kip1). Cell 85: 721-732, 1996.

29. Emons JA, Marino R, Nilsson O, et al: The role of $\mathrm{p} 27^{\mathrm{Kipl}}$ in the regulation of growth plate chondrocyte proliferation in mice. Pediatr Res 60: 288-293, 2006.

30. Macleod KF, Sherry N, Hannon G, et al: p53-dependent and independent expression of p21 during cell growth, differentiation, and DNA damage. Genes Dev 9: 935-944, 1995.

31. Parker SB, Eichele G, Zhang P, et al: $\mathrm{p} 53$-independent expression of p $21^{\mathrm{Cipl}}$ in muscle and other terminally differentiating cells. Science 267: 1024-1027, 1995.

32. Stewart MC, Farnum CE and MacLeod JN: Expression of p21 CIP1/WAF1 in chondrocytes. Calcif Tissue Int 61: 199-204, 1997. 